\title{
"AGORA ENTR
}

ÁGUA”: SOBRE EXPERIÊN

$$
\text { E ESTRATÉGIAS }
$$

SOBREVIVÊNCIA EN

PESCADORES ARTESAN

EM UMA VILA AMAZÔN 


\section{"AGORA ENTROU ÁGUA": SOBRE EXPERIÊNCIA E ESTRATÉGIAS DE SOBREVIVÊNCIA ENTRE PESCADORES ARTESANAIS EM UMA VILA AMAZÔNICA}

DARNISSON VIANA SILVA

UNIVERSIDADE FEDERAL DE CAMPINA GRANDE 


\section{"AGORA ENTROU ÁGUA": SOBRE EXPERIÊNCIA E ESTRA- TÉGIAS DE SOBREVIVÊNCIA ENTRE PESCADORES ARTESA- NAIS EM UMA VILA AMAZÔNICA}

\section{Resumo}

Este artigo versa sobre o modo de vida contemporâneo de uma família de pescadores artesanais no distrito de Alter do Chão, Santarém/PA. Trata-se de estudo exploratório cujas análises buscam estabelecer a hipótese de que os atores sociais envolvidos na pesquisa mobilizam diferentes manobras e estratégias para escapar das dificuldades encontradas no seu ofício "primordial", a pesca. Novas configurações sociais do vilarejo e o avanço de forças econômicas externas tensionam a reprodução social e a condição de pescador artesanal local. Os dados coletados em campo a partir de imersão etnográfica apontam para aspectos do modo de vida desses atores sociais que os aproximam da caracterização de pescadores polivalentes nos termos de Furtado $(1990,1993)$ e os quais sinalizam para a necessidade de uma abordagem que leve em consideração as particularidades histórico-geográficas, trajetórias individuais e situações relacionais. Assim, conclui-se em primeira instância que o entendimento nativo dos pescadores sobre os significados da experiência e da estratégia de sobrevivência é de grande valia tanto nas "artimanhas" para capturar o peixe quanto nas "artimanhas do viver" e que contextos multiculturais em decorrência, sobretudo, da consolidação do turismo na pequena localidade podem gerar novas visões de mundo a partir do contato entre culturas.

Palavras-chave: Experiência, estratégias de sobrevivência, pesca artesanal, Amazônia. 


\title{
“TAKING ON WATER": EXPERIENCE AND SURVIVAL STRATE- GIES AMONG ARTISANAL FISHERMEN IN AN AMAZONIAN VILLAGE
}

\begin{abstract}
This manuscript deals with the contemporary lifestyles of a family of artisanal fishermen in the district of Alter do Chão, in Santarém/PA. It is an exploratory study whose analyses seek to establish the hypothesis that the social actors involved in the study mobilize different maneuvers and strategies to escape the difficulties encountered in their "primordial" craft, the fishing. New social configurations within the village and the advancement of external economic forces complicate the social reproduction and the condition of local artisanal fisherman. The data collected in the field from ethnographic immersion highlights aspects of the way of life of these social actors that approximate them of the characterization of polyvalent fishermen in the terms of Furtado $(1990,1993)$ and which indicate the need for an approach that considers historical and geographical particularities, individual trajectories and relational situations. Thus, it is concluded in the first instance that the native understanding of the fishermen on the meanings of experience and survival strategy is of great value both in the "tricks" to capture the fish and in the "tricks of life" and that multicultural contexts, due mainly to the consolidation of tourism in a small locality, can generate new world perspectives from the contact between cultures.
\end{abstract}

Keywords: Experience, survival strategies, artisanal fisheries, Amazon. 
"SE VINO EL AGUA": DE LA EXPERIENCIA Y LAS ESTRATEGIAS DE SUPERVIVENCIA DE PESCADORES ARTESANALES EN UN POBLADO AMAZÓNICO

\section{Resumen}

El presente articulo se trata del estilo de vida contemporâneo de una familia de pescadores artesanales del distrito de Alter do Chão, Santarém/PA, Brasil. Se trata de un estudio exploratorio cuyo análisis busca establecer la hipótesis de que los actores sociales involucrados en la investigación utilizan diferentes maniobras y estrategias para escapar de las dificultades encontradas en su oficio "principal", la pesca. Nuevas configuraciones sociales del poblado y el avance de las fuerzas económicas externas tensionan la reproducción social y la condición del pescador artesanal. Los datos recogidos en campo, a partir de la inmersión etnográfica, apuntan a aspectos del modo de vida de estos actores sociales que los aproximan a la caracterización de pescadores polivalentes, de acuerdo con la visión de Furtado (1990, 1993), lo que indica la necesidad de un abordaje que considere las particularidades histórico-geográficas, las trayectorias individuales y las situaciones relacionales. En primer lugar se concluye que la comprensión nativa de los pescadores sobre los significados de la experiencia y de la estrategia de supervivencia es de gran valia, tanto en la artimañas utilizadas para capturar al pez como en las "artimañas para vivir". Y que los contextos multiculturales que se están dando, sobre todo de consolidación del turismo en pequeñas localidades, pueden dar lugar a nuevas visiones del mundo a partir del contacto entre culturas.

Palabras clave: Experiencia, estrategias de supervivencia, pesca artesanal, Amazonía

Darnisson Viana Silva

darnissonviana@yahoo.com.br 


\section{INTRODUÇÃO}

As transformações socioespaciais com vistas à maximização do lucro na economia brasileira se dão em diversos setores da cadeia produtiva e da sociedade e geram impactos profundos no modo de vida de inúmeros agentes sociais, sobretudo, aos chamados povos tradicionais. $\mathrm{Na}$ Amazônia este processo tem se revelado como propulsor de rearranjos estratégicos de sobrevivência pelos quais o homem amazônico tem procurado mobilizar para manter sua reprodução social e sua condição de vida (Furtado 2002 et al., Lima 2002, Santana 2002, Loureiro 2009). Muitos dos problemas, observados pela literatura especializada, estão relacionados a grandes empreendimentos de capitais para abastecimento e escoamento da produção local, seja no setor madeireiro, de minérios, do agronegócio ou da pesca em grande escala. No presente artigo focaremos análise na categoria do pescador artesanal ou pescador polivalente (Furtado 1990, 1993) como um importante agente social que habita diferentes territorialidades agora não somente vinculado aos ambientes da floresta e dos recursos aquáticos, mas também intimamente ligado à cidade e aos recursos que dela dispõe, bem como das dificuldades de trabalho por eles vivenciados.

O presente ensaio delineia-se a partir de uma comunidade amazônica às margens do rio Tapajós, no estado do Pará. A vila ${ }^{1}$ de Alter do Chão, distrito do município de Santarém, é hoje um importante atrativo de lazer no translado das cidades de Belém, Santarém e Manaus, e configura intenso fluxo tu- rístico impulsionado pela exuberância das belezas naturais do lugar e por investimentos de capital estrangeiro que pouco a pouco vão transformando, significativamente, a paisagem local, principalmente no município de Santarém devido à incorporação da região à expansão do agronegócio mais contemporânea (Cortês \& D’antona 2016). O novo contexto do qual se encontra a localidade permite, numa perspectiva mais ampla, destacar elementos que expressam a complexidade da reconfiguração rural na Amazônia, até mesmo podendo se alinhar a discussão das metamorfoses ou da diversidade campesina amazônica (Moreira \& Hébette 2009). Nossa preocupação, no entanto, se restringe as situações relacionais, empiricamente observadas e expressas, contudo, nos elementos auto-identificadores (materiais e imateriais) no cotidiano dos atores sociais aqui tratados. A ênfase, portanto, é menos estabelecer uma teoria ou produzir novas terminologias para o campo abordado do que, propriamente, compreender os novos tensionamentos vividos pelos agentes sociais [pescadores artesanais] e as respostas dadas pelos mesmos em contextos específicos. É importante esclarecer que o estudo se encontra em andamento para elaboração de tese de doutorado e os dados coletados até o presente momento se sobrepõe a uma família de pescadores que julgamos congregar os elementos buscados na análise, bem como da profundidade das observações.

O campo teórico-conceitual que utilizamos procura dialogar com a perspectiva que leva em consideração os aspectos fundamentais dos relacionamentos dinâmicos da cultura. Para tan- 
to, as contribuições de Barth (2000a, 2000b, 2005) vão nortear o caminho percorrido trazendo à baila estudos cuja literatura foque o vilarejo, a região da bacia Amazônica e outras partes litorâneas do Brasil, haja vista que estes processos particulares não podem ser entendidos totalmente desconectados de processos mais gerais. Por outro lado, questões de natureza das relações de trabalho, meios produtivos e reprodução social encontrariam terreno fértil em outras perspectivas teóricas ${ }^{2}$, mas o objetivo do presente texto não permite, nos limites de seu propósito, uma análise minuciosa da natureza destas relações, as limitamos optar por um olhar, eminentemente, antropológico.

As noções de experiência e estratégia de sobrevivência são inspiradas, respectivamente, nos escritos de Walter Benjamim (1994) e Lourdes G. Furtado (1993, 2002); Marta Goreth M. Lima (2002, 2008) que julgamos pertinente na apreensão do que significa em tempos atuais e no âmbito da pluriatividade do pescador nesta microrregião, a expressão "batalhar para viver" ou "se virar para inteirar o pirão" 3 . A metodologia, portanto, é a observação participante e partimos da postura desenvolvida por DaMatta (1978) e muito bem aproveitada por Dawsey (2013), em seu trabalho de campo com trabalhadores rurais no interior do Estado de São Paulo, no que diz respeito ao processo de empatia interpessoal entre pesquisador e pesquisado na produção social dos eventos. Assim, "brincamos" com o perigo e tentamos colocar à prova nossas ideias preconcebidas na academia no que concerne à organiza- ção social de populações tradicionais, em meio às ações no cotidiano de uma família de pescadores no bairro do Jacundá, em Alter do Chão-PA.

Dessa forma, localizamos a compreensão do que chamamos de pescador polivalente no atual contexto da vila a partir de um - paralelo - com o entendimento de Furtado (1990, 1993, 2002) acerca do modo de vida do pescador e suas estratégias de subsistência na região do estuário do rio Amazonas, bem como buscamos refletir sobre a adequação deste entendimento face à realidade da comunidade estudada. Vale ressaltar, que em nosso entendimento o sentido do termo, talvez, extrapole o da autora, na medida em que damos vazão à versatilidade ampla do agente social pescador nas condições que ele se encontra no mundo contemporâneo globalizado. Nessa perspectiva, consideramos relevante realizar um breve estado da arte sobre a atividade de pesca na região da Amazônia Paraense e com algum esforço em Alter do Chão, visto que a literatura sobre o tema em relação à localidade específica não é das mais generosas. Por fim, algumas perspectivas de análise quanto ao agente pescador artesanal e suas possíveis definições.

A partir disso, portanto, nossa atenção aqui se ergue da conjectura de que novos processos de reterritorialização dos espaços da pesca (Furtado 2015, comunicação verbal) ${ }^{4}$ precisam ser mais bem assinalados, discutidos e analisados aos olhos das ciências sociais e aos olhos da antropologia ou como querem alguns uma socioantropologia da pesca (Diegues 1995, Silva 2012, 2014, 
Ramalho 2016) cuja produção possa, em alguma medida, dar embasamento no planejamento de políticas que atendam as demandas e busquem a melhoria de vida destes agentes sociais tão importantes na configuração do espaço amazônico.

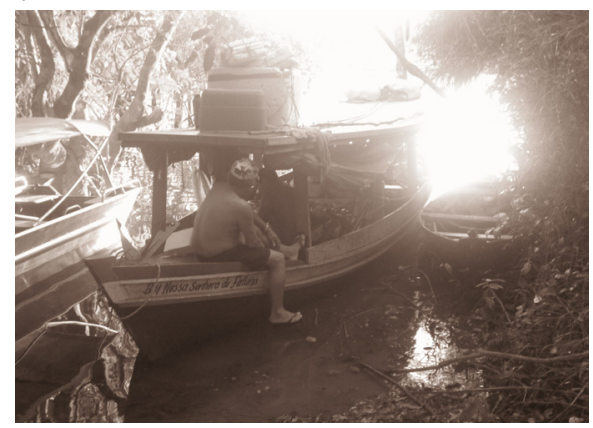

Figura 1 - Pescadores na boca do lago do Jacundá - Alter do Chão/PA. Foto: Silva, Darnisson Viana, 2015.

\section{ALGUNS ELEMENTOS CONFLITAN- TES SOBRE A PESCA NA AMAZÔ- NIA PARAENSE E ALTER DO CHÃO}

Como é sabido, "A pesca artesanal no Brasil [como na Amazônia] é marcada pela diversidade e complexidade de sujeitos, ambientes, pescados, embarcações, técnicas e artes de pesca, assim como pelo modo de vida das comunidades" (Moreno 2015:1). Na região amazônica podemos cogitar, inspirados em estudos desta e de outras regiões (Marques 1991, Begossi et al. 2004), que historicamente, o pescador artesanal desempenhou e desempenha papel fundamental no equilíbrio ecológico dos ecossistemas presentes, sobretudo, no que diz respeito à ecologia dos peixes. Por certo, constitui uma das atividades extrativas mais tradicio- nais e antigas que o habitante deste lugar exerce (Furtado 1997), sem dúvida, herdeiros de conhecimentos vindouros de populações primordiais, os indígenas. Mas, atualmente os pescadores artesanais e boa parte das comunidades ribeirinhas que dependem desta atividade vêm enfrentando vários problemas que segundo Loureiro (2009) tem raízes históricas no modelo econômico concebido e implantado pela ditadura militar, na pretensão de "desenvolver" a região no final do século $\mathrm{XX}$.

"Quatro atividades econômicas básicas foram incentivadas pelas políticas dos governos militares para a região: na primeira fase 1970/1985, a extração da madeira, a pecuária e a pesca industrial; e na segunda fase 1986/2000 em diante, planejada ainda durante a ditadura, mas que perdura sem grandes correções até hoje, tem a mineração, a moderna pecuária como pontos centrais, às quais se adiantaram os grãos. Eram os produtos que, segundo análises econômicas feitas na época, apresentavam boas chances de aceitação no mercado externo" (Loureiro 2009:57).

Entretanto, segundo a autora, as análises e as estratégias adotadas pelo governo da época não levaram em consideração os impactos perversos que tais atividades provocariam na base produtiva em que se apoiavam as atividades das populações tradicionais e suas formas de vida. Nada se fez para pensar formas alternativas de crescimento econômico que levasse em consideração a existência dos atores sociais locais que possuem íntima relação de dependência dos recursos da natureza, 
bem como extrai destes o seu meio de subsistência. Assim, no caso da pesca, grandes embarcações pesqueiras foram financiadas por programas do Governo Federal sem análise do estoque pesqueiro disponível, "certamente por considerá-lo inesgotável, com vistas a modernizar a pesca na Amazônia" (Loureiro 2009:59, grifo do autor). Face aos desdobramentos desta política de outrora e às questões mais contemporâneas de modernização do setor pesqueiro, os conflitos por apropriação dos espaços da pesca permanecem e, por vezes, se acirram de maneira violenta dependendo da disputa de certos territórios e de certos atores envolvidos.

"A grande pesca hoje é praticada nos moldes empresariais, com alto grau de modernização, em seu processo de captura e beneficiamento, cujas relações de trabalho são de caráter capitalista" (Lima 2008:37).

Em algumas partes da Amazônia brasileira, essas embarcações modernas, equipadas com caixas de gelo triturado e revestido de gelo seco são conhecidas como geleiras e algumas podem ter a capacidade de carregar até 50.000 quilos de gelo (Martins 2009:61). As geleiras são, por lei, proibidas de realizar capturas em águas interiores, mas a falta de fiscalização muitas vezes deixa o caminho livre, sem qualquer obstáculo, para esses pescadores assalariados ${ }^{5}$. Tal situação gera, por conseguinte, os tensionamentos e os conflitos abertos com populações de pescadores artesanais organizados (Associações, colônias e conselhos de pesca) de algumas localidades do Baixo Amazo- nas, como atestam Moreira \& Hébette (2009) no município de Porto de Móz (PA):

"O tratamento da questão da pesca foi mais complexo: fizeram alguns seqüestros de equipamentos e até de barcos invasores de seus territórios pesqueiros tradicionais; houve alguns acordos internos de pesca (proibição de uso de redes malhadeiras, respeito ao período de piracema, proibição de barcos geleiros no lago do Urubu), mas interesses divergentes tornaram difíceis acordos mais amplos" (Moreira \& Hébette 2009: 203).

A pesca dita industrial é um problema sério e vários estudos (Loureiro 1983, Mello 1985, 1995, Mello et al. 1993, Santana 2002) vêm abordando a evolução de sua atuação [predatória] em algumas localidades ao longo desses últimos anos. Sua continuidade afeta, sem dúvida, uma cadeia enorme de relações ecossistêmicas e ecossociais ${ }^{6}$ (Ramalho 2016) e pode gerar impactos duradouros em ambientes ainda desconhecidos pela ciência, uma vez que a natureza responde de maneira imprevisível às ações antrópicas intensas.

"A atividade pesqueira não se reduz a um âmbito espacial homogêneo, mas a diferentes ecossistemas, complexos, frágeis e muitas vezes desconhecidos, isto é, sistemas vastos de interdependência atendendo a mobilidade dos recursos pesqueiros. Compreende-se, por conseguinte, que a pluralidade de ecossistemas aquáticos gere múltiplas implicações, pressupondo que ocorrem adaptações culturais, modos de qualidade de vida e formas 
de organização diversas" (Martins 2009:26-27).

As condições de reprodução social e dos recursos no território vêm mudando na Amazônia, e em Santarém (PA) com consequente redução da ictiofauna regional. Apesar do sistema social local, o mercado e a comercialização têm mostrado que ele se adapta às mudanças em curso, sobrecarregam o manancial de recursos e colocam em risco a possibilidade de sustentabilidade ambiental e econômica (Martins 2009). Vejamos mais adiante como essas transformações têm afetado a vila e a comunidade focada no presente estudo.

\section{O UNIVERSO EMPÍRICO DA PES- QUISA}

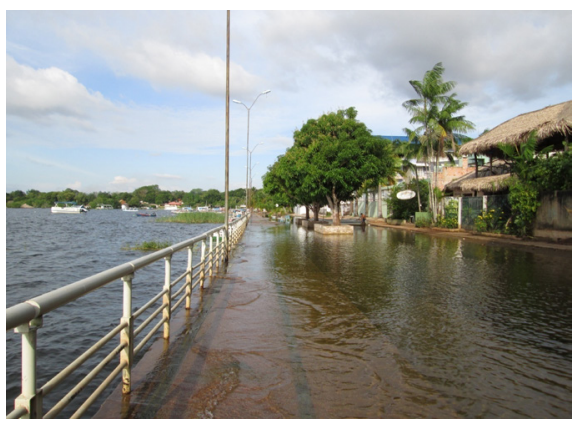

Figura 2 - A orla de Alter do Chão durante a cheia do rio Tapajós. Foto: Silva, Darnisson Viana, 2016.

A vila de Alter do Chão possui uma população de aproximadamente 6.000 habitantes e está localizada na planície do rio Tapajós, afluente direto do rio Amazonas. Distante a $34 \mathrm{~km}$ do município de Santarém, sua principal referência. É bem verdade que dificilmente ocorre falar de Santarém sem mencionar "Alter" (e vice-versa) pela importância econômica das duas localidades para a região, a qual se situa a meio caminho entre Belém e Manaus - as duas maiores cidades do perímetro que chamamos de Amazônia brasileira. Uma viagem de Belém à Santarém pode demorar uns três dias de barco devido às estradas não terem boas condições de tráfego ou em média uma hora por transporte aéreo. Santarém, Alter do Chão e adjacências constituem territórios marcados por novas configurações nos contextos rurais e urbanos em decorrência da recente inserção no agronegócio. Estudos recentes tem se efetuado em direção as questões da mobilidade populacional e apresentando outros quadros de percepção diferentes das pressuposições de análises anteriores.

"À medida que o espaço rural se aproxima das condições urbanas, ocorre redução na produção de alimentos notificada em Santarém, associada à expansão da soja por Carvalho e Tura (2006), sendo isto também consequência desta nova configuração rural, com propriedades cada vez menores e atividades não agrícolas mais valorizadas (Silva; Del Grossi, 1998). Essa transformação nos valores rurais ajuda a explicar as mudanças nas tendências de migração de jovens homens e mulheres averiguadas em Santarém, já que os fatores de atração e de repulsão populacional sofrem modificações significativas e alteram a percepção de oportunidades desses jovens" (Cortês \& D'antona 2016:426).

Em Alter do Chão, esse processo é pouco observado ou mesmo estuda- 
do. Além disso, a vila está localizada numa área [terra firme] que tramitam disputas e processos jurídicos, em instâncias federais, por reconhecimento territorial de pertencimento étnico-indígena ${ }^{7}$, o que torna o dinamismo das discussões políticas concentradas em torno dessas e outras questões administrativas. Contudo, a vila não está isenta das influências do que acontece na cidade, isto é, dos embates do conjunto de forças político-econômicas atuantes no município próximo, o que gera uma relação de interdependência muito clara ${ }^{8}$. No que tange as atividades econômicas que prevalecem no vilarejo e atuam de modo direto no modo de vida da população local, encontram-se aquelas vinculadas aos diversos ramos do Turismo: hotelaria, pousadas, restaurantes, comércio, passeios fluviais, passeios terrestres, visitas a áreas de proteção ambiental e reservas extrativistas, retiros espirituais, pescarias esportivas, festas religiosas e festivais folclóricos. Os registros a seguir ilustram uma pequena parte deste universo.

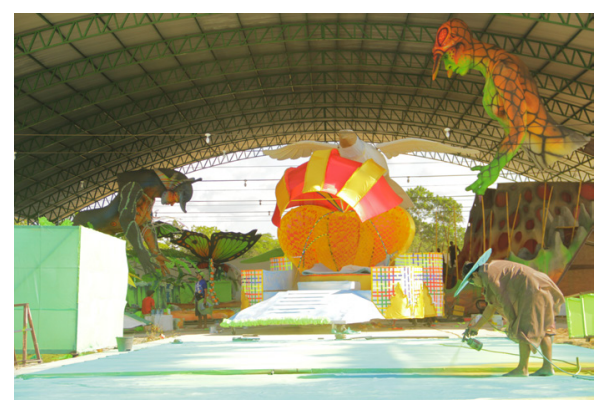

Figura 3 - Barracão dos Botos, confecção das alegorias do festival. Coleção do autor. Foto: Palestina Israel, 2014.

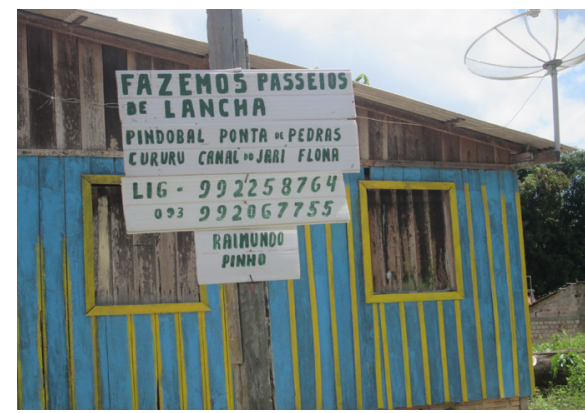

Figura 4 - Serviços de passeios turísticos em Alter do Chão. Foto: Silva, Darnisson Viana, 2016.

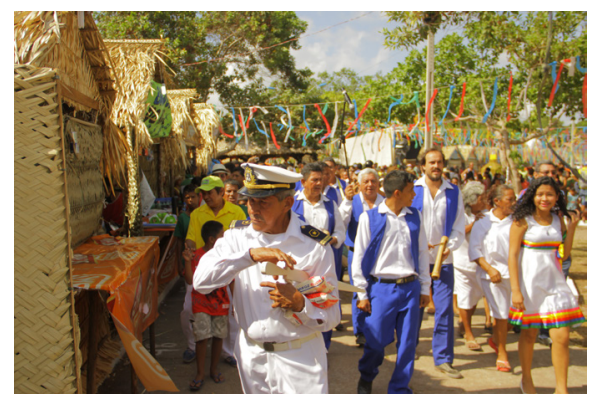

Figura 5 - "Sairé religioso" em Alter do Chão. Coleção do autor. Foto: Palestina Israel, 2014.

Numa pesquisa realizada para avaliar a percepção dos moradores em relação à importância das diferentes atividades econômicas para sua subsistência foi constatado que 36\% das famílias entrevistadas da amostra ${ }^{9}$ declararam que possuíam membros da família envolvidos direta ou indiretamente com a atividade turística (Costa 2005). No mais, 67,6\% declararam que possuíam pelo menos um membro da família que pescava na região. Segundo o mesmo autor, a comunidade ainda mantém uma forte relação com a pesca de subsistência, indicando que a incorporação do turismo como atividade econômica não alterou a importância da pesca na vida dos moradores $^{10}$. 
"O resultado reflete tanto a forte relação das comunidades locais com a atividade de pesca como a necessidade da maioria das famílias de se dedicar a diferentes atividades econômicas ou extrativas como forma de assegurar sua subsistência. $\mathrm{O}$ fato da comunidade ter demonstrado consciência da importância das atividades ligadas à pesca e ao turismo como meio de subsistência pode ser um ponto de apoio importante para a conservação dos sistemas aquáticos de Alter do Chão" (Costa 2005:104).

Em suma, os aspectos colocados sobre a região de Alter do Chão e Santarém e apontados até aqui nos trazem elementos sobre processos específicos de reordenamento socioespacial, mudanças no modo de reprodução social dos atores locais em foco [pescadores artesanais] e situações relacionais no mundo do trabalho, bem como múltiplas maneiras de buscar sobrevivência dos sujeitos analisados. Tais elementos nos informam, de alguma maneira, acerca de uma tendência de processos de ressignificações simbólicas e materiais vividos por populações tradicionais da Amazônia que hoje veicula novas configurações de lidar com a vida, levadas a cabo por novos atores contemporâneos, cujas práticas têm sido abordadas pela comunidade científica em diversas perspectivas e que procuramos examinar no tópico seguinte.

\section{HIPÓTESES E PERSPECTIVAS, INDÍ- CIOS E EVIDÊNCIAS}

Estamos convencidos, de que boa parte, das produções intelectuais mais re- centes voltadas ao tema da produção pesqueira e populações tradicionais na Amazônia, explora questões importantes no entendimento de processos ecossociais (Ramalho 2016) encontrados na região. Um ponto nevrálgico e divergente diz respeito a perspectivas que consideram a categoria da pesca artesanal, no Baixo Amazonas, como parte de um campesinato regional histórico e em modalidades distintas no tempo e espaço.

"Em nosso entendimento, esse modo de vida camponês abrange uma variedade de atividades produtivas; não só as ligadas à agricultura ou a criação de animais, como também à pesca dita artesanal e a tantas outras formas de extrativismo" (Hébette et al. 2002:2, grifo nosso).

Segundo Moreira \& Hébette (2009) o campesinato é um modo de vida específico, "marcado, principalmente, pela relação direta de determinados grupos rurais com a natureza como base de sua produção material e de sua reprodução social, e por sua organização social baseada na família nuclear, no parentesco e na convivência coletiva em vizinhança" (Galeski 1977, Shanin 1976 apud Moreira \& Hébette 2009:187). Ao analisar o cotidiano de camponeses de uma região do Baixo Amazonas Moreira e Hébette (2009) assinalaram uma mudança significativa nesse modo de vida coletivo, "expressa na mudança multiforme de autodenominações identitárias [...] que, "fazem referência tanto à atividade e à localização geográfica quanto à condição jurídica e à etnia" (Moreira \& Hébette 2009:187188) destacando que tais populações mestiças daquela área sofreram, no 
decorrer dos dois últimos séculos profundas transformações em sua organização social, seu modo de vida e sua identidade. Klaas Woortmann (1990) por seu turno, já chamava atenção para esta ambigüidade histórica no sentido de que "na Amazônia, convivem concepções sobre a terra que chamo de morais (terra enquanto valor-de-uso) com concepções utilitaristas mercantis" (Woortmann 1990:4, grifo nosso). Segundo o autor, os camponeses da Amazônia não são camponeses puros, mas possuem a qualidade da campesinidade ${ }^{11} \mathrm{em}$ graus distintos de articulação ambígua com a modernidade.

Tratando-se do ecossistema de várzea desta região, outra perspectiva é elaborada na tese de doutorado de Cruz (2007) focando a questão da territorialidade. Segundo o autor a caracterização do campesinato na várzea amazônica pode ou precisa ser entendida como processo, jamais desvinculado com as sociedades envolventes, portanto, considerando suas características gerais e específicas marcadas, por vezes, por mudanças significativas em sua relação com a natureza. Para este morador/trabalhador/pescador da várzea, o autor elabora o termo "camponês-ribeirinho" como forma de contemplar seguindo as pistas de Shanin (1980) o ser social camponês e o ser social ribeirinho (Castro 1997). A idéia de ser social camponês está vinculada a idéia da pequena unidade de produção-consumo baseada na agricultura e no trabalho familiar, bem como as relações sociais daí decorrentes. Já o ser social ribeirinho remete a imagem do quadro de percepções e conhecimen- tos que o morador da beira do rio tem dos recursos da floresta e dos cursos d'água, entre lagos, igarapés e paranás, fundamentados em sistemas de classificações próprios e no seu patrimônio cultural (Castro 1997).

Partindo desse pressuposto, a ideia de "camponês-ribeirinho" estaria inclusa na perspectiva de Jan Douwe van der Ploeg (2008) quando diz que "a maioria dos grupos agrários de hoje são constituídos por uma 'mistura' confusa e altamente diversificada de diferentes modos de fazer agricultura" (Ploeg 2008:34). Alguns desses modos estão próximos ao modo camponês ${ }^{12}$, outros obedecem a uma lógica com outras finalidades e diferenças. Aqui, reside fundamentalmente o ponto crítico de nosso argumento e de nossa proposta de investigação, uma vez que a pescaria e pescadores $^{13}$ artesanais de Alter do Chão, embora possuam as características orgânicas de um campesinato [organização social baseada na família nuclear, no parentesco e na convivência coletiva em vizinhança] nos termos tratados até aqui, não estão, até onde pudemos observar em pesquisa de campo, atrelados exclusivamente ao ofício da pesca enquanto base de sua reprodução material e social. Novas configurações socioeconômicas, hoje tornam estratégicos e situacionais os engajamentos dos pescadores na luta pela sobrevivência de seus domínios familiares. Se num primeiro momento histórico ${ }^{14}$ a pescaria, enquanto "finalidade presente na ideação do trabalho do pescador, com seus valores, necessidades e possibilidades socioambientais" (Ramalho 2016: 409) representava a base consti- 
tutiva do ser pescador, agora, em nosso caso específico, ela ocupa um terreno um tanto ambíguo cujos valores são redirecionados e orquestrados conforme as necessidades básicas mais imediatas e diversas no emaranhado de relações que o mesmo se encontra. Em certas ocasiões, durante o trabalho de campo, percebemos que muitas vezes nossos interlocutores enredavam discursos multilocalizados e não lineares, que expressavam de forma muito espontânea seus elementos identificadores de acordo com cada contexto. Partindo desse pressuposto é que buscamos avaliar como uma família de pescadores artesanais em "Alter" tem procurado redimensionar seu modo de vida em função da experiência dos mais velhos e das estratégias adotadas para a sobrevivência do dia a dia.

\section{EXPERIÊNCIA E ESTRATÉGIAS: DE COMO VIVER TEM DE SUAS "ARTI- MANHAS"}

"Deus me deu uma profissão muito boa...que hoje eu agradeço que é a "construção" [construção civil] ... eu sempre trabalhei muito bem nela..." ("Bodó"15, na taberna da Lôra, 14/09/2016).

Seu "Bodó" nasceu em 1952 na cabeceira de uma comunidade distante ao longo do rio tapajós e veio se criar na cidade quando adolescente. Chegou a viajar à Manaus, Belém, Mato Grosso e Goiás. Hoje vive em Alter do Chão a mais de trinta anos. É um desses pescadores que não tem "tempo ruim", dificilmente é de encontrá-lo de temperamento ruim, ou de mau humor, seu sorriso é, por demais, espontâneo e sempre tem uma história ou uma anedota na memória e na ponta da língua para contar. Quando interpelado a respeito de sua trajetória de vida e de pescador, ele esclarece:

“Eu comecei a pescar em 1973, só mais tarde quando eu era da colônia e tinha carteirinha, eu pagava aquela taxa, agora não que eu não pago mais nada... [gargalhadas], mas de lá pra cá, Paraná ${ }^{16}$ ! eu não parei mais...Deus me ajuda e eu sempre faço minha pescaria!" ("Bodó", no quintal de sua casa, 15/06/2016).

O pescador aludido é o "patriarca" de uma família numerosa a qual vive debaixo do mesmo teto seis crianças pequenas [os netos], a esposa "Dona Pescadinha", praticamente a "mãe de todos" [que cuida de todos], uma filha solteira, uma filha casada e, portanto, o esposo mora de agregado, dois filhos rapazes, ao fundo da casa no mesmo terreno vive a família de outro filho mais velho [primogênito] com uma esposa e quatro filhos (dois adolescentes). Mais adiante em outra casa, que acabara de ser construída no quintal do terreno, ainda com o piso de terra batida, "o filho do meio" com a esposa e duas crianças pequenas. Os outros filhos (as) possuem outros endereços na vila, mas frequentam a casa com regularidade e até se alimentam na mesma. Assim, se configura a casa deste pescador a qual parece obedecer a um padrão observado por Furtado (2002) em certas comunidades pesqueiras do Estado do Pará. “O padrão residencial tende a seguir os laços familiares. Filhos procurando residir às proximidades dos pais, filhas sem marido buscam 
o apoio dos pais na criação e manutenção de seus filhos. Os pais reconhecem que devem dar apoio nessas situações" (Furtado 2002: 40). Seu "Bodó", em certa ocasião, tentou me explicar o que é ter a responsabilidade de ser "O homem da casa".

"Paraná, o homem da casa precisa ser firme em tudo que decidir... minha "Pescadinha" [esposa] comanda tudo, ela é quem bota essa cambada pra se sacudir quando vê que já tão tudo na costa dela...ela faz o dinheiro dela pra lá...quando vê ela tá chegando...arrumando as coisas por ali...quando vê ela tá estressada... Olhe! Eu to bem aqui... Ninguém sabe o que se está passando na minha cabeça... às vezes, tô com um problema assim, assado, mas eu nunca demonstro! Paraná, eu não demonstro sabe por quê? Porque senão eu to sendo fraco aí eu perco o comando do barco... eu tenho que fazer a minha parte! Quando o bicho pega pra valer eles corre tudo comigo, esses bando de C...[gargalhadas]" ("Bodó", no quintal de sua casa, 02/08/2016).

Ao passo que fomos conquistando a empatia de "Dona Pescadinha" outras percepções foram sendo engendrados, os significados das estratégias de sobrevivência foram se alargando e os dimensionamentos dos recursos foram tornando-se mais concretos para fins de análise. "Dona Pescadinha" certa manhã se queixou.

"É difícil, porque já não vejo o dinheiro que ele faz por aí [Bodó] olhe! Aqui são seis crianças pequenas, fora os filhos grandes que são dois aí tem as namoradas e ainda três casados praticamente tudo no mesmo teto. Eu recebo quatrocentos reais onde eu trabalho, lá na casa da comadre, mais cento e oitenta do Bolsa Família, de três crianças que eu cadastrei que os outros eu num sei o que aconteceu num veio mais e eu tenho que dá conta de tudinho, quando ele ainda vai pescar eu vejo alguma coisinha, mas se não for..Hum! hoje eu cheguei foi morta de cansada que tive que molhá as plantas, porque eu molho quase todo dia..." ("Dona pescadinha", no quintal de casa para um cafezinho, 07/08/2016)

Como podemos identificar os programas sociais do Governo Federal, tal como o "Bolsa Família" 17, atende a uma população economicamente desfavorecida e compõe, de fato, a renda daqueles que encontram-se em situação de vulnerabilidade socioeconômica. Assim, no caso observado, acabam tornando-se também "arranjos adaptativos que se realizam no agregado familiar, nos grupos ou comunidades, visando maximizar a renda e o consumo, assegurando dessa forma a manutenção da família" (Haguette apud Oliveira \& Ribeiro Neto 1989). Ademais, outros estudos apontam que a combinação de renda com mais de um tipo de atividade econômica é uma necessidade e uma característica fundamental de populações que dependem dos recursos naturais. As estratégias instauram-se através da combinação de atividades condicionadas pelo acesso dos recursos (Lima 2008). Tais elementos podem ser encontrados na seguinte fala do pescador:

"Paraná! eu tenho muita pena desse pessoal que vem de fora, que fica 
por aí sabe Deus como, nós aqui se vira por ali...quando não... joga uma malhadeira... pega um peixinho...outro dia o compadre me convidou pra caçar.... só num fui porque ele desmarcou.., mas nós temo uma vida muito boa aqui, ninguém passa fome...graças a Deus!" ("Bodó", na taberna do seu Neuto, 14/09/2016).

Outra perspectiva rica para o entendimento de tais processos é dada por Furtado (2002) para quem o sentido atribuído às estratégias de subsistência, incorpora as ações que são empreendidas para obtenção dos recursos necessários do cotidiano dos grupos domésticos. Estas ações podem ser a pesca, a coleta, serviços prestados na comunidade, todas contribuem para a fruição dos bens materiais necessários ao cotidiano e a seus ritos.

Outro dado importante e que deve ser analisado com mais acuidade é a questão do contato cultural. Em outra ocasião pudemos conjecturar a respeito de fluxos culturais globais que atravessam o vilarejo, nas últimas décadas, em decorrência de intensa mobilidade de turistas, forasteiros, viajantes, transeuntes e mais, recentemente, pesquisadores de toda parte e origem que aportam em Alter do Chão e, por ali, se estabelecem por algum tempo. A convivência mais estreita com diferentes grupos sociais e, por vezes, de origem étnicas distintas geram, na prática situações de troca inevitáveis e com as quais remodelam as percepções de mundo dos atores envolvidos. Tal contexto acaba promovendo experiências socioculturais únicas e apontam, consistentemente, para o que Barth (2005) sugere:
"Devemos pensar a cultura como algo distribuído por intermédio das pessoas, entre as pessoas, como resultado das suas experiências. Ao terem experiências semelhantes e se engajarem mutuamente em reflexões, instruções e interações, as pessoas são induzidas a conceitualizar e, em parte, compartilhar várias modelos culturais. Sugiro que um aspecto crucial das coisas culturais é a forma pela qual elas se tornam diferencialmente distribuídas entre pessoas e entre círculos e grupos de pessoas" (Barth 2005: 17).

Para ilustrar um pouco sobre algo que pode ser útil para pensarmos nesse sentido, recordamos uma situação em campo, a nosso ver irônica, do ponto de vista das construções imaginárias românticas que comumente se faz de populações tradicionais e seu universo de procedimentos. Certa ocasião, um alemão proprietário de uma pequena embarcação, interessado nos conhecimentos sobre a pesca local me questionou sobre como os pescadores, os quais eu convivia, faziam quando os botos $^{18}$ furavam/rasgavam suas redes em plena pescaria, se eles destinavam um tempo a costurá-las para em seguida reutilizá-las. Certamente, lhe expliquei que os mesmos que observei não o faziam uma vez que despendia muito tempo e trabalho e os botos certamente voltariam a rasgá-las. No entanto, recordamo-nos de imediato a fala de "Charutinho" quando ousamos lhe perguntar o que estava fazendo no finzinho da tarde.

"Olha parceiro! a pessoa tem que se virá quando quer pegar o peixe, quando não dá... a gente com- 
pra lá no China!... [gargalhadas]"

("Charutinho", remendando a malhadeira no quintal de sua casa, 10/07/2016).

Deste modo, ao conjunto das representações multifacetadas encenadas pelos nossos interlocutores parecem também compor, por assim dizer, as estratégias de relacionamento que irão beneficiar o leque de possibilidades de ganhos do pescador polivalente na diversificação do seu trabalho. No que diz respeito ao significado de polivalente, explicitemos:

"Que apresenta múltiplos valores ou oferece várias possibilidades de emprego; multifuncional; que executa diferentes tarefas; versátil; que envolve vários campos de atividade; que serve para diversos fins" (Houaiss 2004:580).

Portanto, são muitas as atividades realizadas pelos pescadores os quais tivemos oportunidade de observar em campo que vai desde jardineiro, pedreiro, caseiro de mansões à segurança de casa de shows. Ao cabo, nenhuma delas obteve registro em carteira profissional de trabalho tampouco receberam cursos de aperfeiçoamento ou capacitação. Tem-se o "privilégio" de umas serem mais freqüentes que as outras como a de pedreiro. Decerto, os arranjos aconteciam por intermédio de uma rede de indicações, onde um compadre indica o outro e assim por diante e, muitas vezes, o que tem peso na ordem é aquele considerado mais necessitado. Conforme nos relatou "Charutinho" esperando a carona de moto.

"Parceiro! Seu "J" é danado...ele num perde não ...ele me arruma este serviço de cortar grama, mas ele fica com 30\% do que eu recebo...porque a máquina é dele, então ele tá certo, a máquina, parceiro, é uma beleza! Num estante ela já cortou tudinho e eu fico com os setenta..." ("Charutinho", esperando na taberna do Neuto, 11/072016).

Para Furtado (1990, 1993) a figura do pescador polivalente se estabelece em contraste com o pescador monovalente ou aquele que faz da pesca sua principal atividade econômica seja nas regiões de lagos, rios ou nas faixas costeiras. Mesmo que esta expressão seja elaborada para caracterizar a figura do "pescador-lavrador" que a autora encontrou em certas regiões do estado do Pará, sinalizando para os escritos de Jorge Hurley (1933) na década de trinta, nos sentimos a vontade para nos apropriarmos e adensarmos com outros sentidos mais contemporâneos. Assim, procuramos compreender os descritores que fazem a diferença na comunidade abordada e nos agentes sociais envolvidos em nosso estudo. Por exemplo, postular que hoje o que determina a condição de pescador artesanal em "Alter" tem menos a ver com a freqüência com o que o sujeito sai para explorar o pescado nos rios, lagos e enseadas do que a detenção daquele regime de conhecimento imbricado na prática tradicional da pesca e que só encontra respaldo através da experiência do sujeito, assim, objetivada.

Walter Benjamin (1994) já assinalava, em seu texto seminal sobre a figura do narrador, a importância do significado da experiência em tempos em que a tradição e os seus valores já não encontram 
a mesma centralidade na vida moderna. Aqui, a figura do pescador artesanal tal como a do escasso narrador do final do século XIX compõe o arquétipo do sábio que ao longo de sua existência e de suas experiências, aprendizados, acúmulo de valores ligados ao modus vivendis de sua cultura ${ }^{19}$, ou melhor, de seu grupo social, possui a autoridade e a legitimidade de comunicar aos pares mais jovens, "o que deve ser feito" e "como deve ser feito" ou "como já foi um dia" com a finalidade honrosa de ensinar e perpetuar o conhecimento.

"A narrativa, que durante tanto tempo floresceu num meio de artesão - no campo, no mar e na cidade -, é ela própria, num certo sentido, uma forma artesanal de comunicação. Ela não está interessada em transmitir o "puro em si" da coisa narrada como uma informação ou um relatório. Ela mergulha a coisa na vida do narrador para em seguida retirá-la dele" (Benjamim 1994: 205).

Em relação também de como a "experiência" pode moldar certos "itens de cultura" no relacionamento dos indivíduos em contextos específicos caberia as orientações de Barth (2005) para nossas reflexões sobre o entendimento do conceito de cultura de forma mais ampla e mais profunda nos horizontes aqui tratados.

"Todos concordamos que a cultura se refere a algo (tudo?) que é aprendido. Mais precisamente isso significa que a cultura é induzida nas pessoas por meio da experiencia - logo, para identificá-la, temos de ser capazes de apontar para essas experiências. Temos também que aceitar as seguintes implicações: que a cultura deve ser constantemente gerada pelas experiências por meio das quais se dá o aprendizado. Assim, temos de ter um foco - não para afirmar que a cultura é localizada em algum lugar, mas como uma forma de identificar onde ela está sendo produzida e reproduzida" (Barth 2005: 16, grifos nosso).

Assim, há um elemento que perpassa as duas dimensões apontadas anteriormente que não podemos deixar de mencionar que é a troca intergeracional. O envelhecimento como faceta desta troca aparece como elemento fundamental para pensar questões atuais no mundo da pesca artesanal.

"O conjunto de técnicas, saberes e conhecimentos das gerações mais velhas, constituem-se suporte para um processo social de construção de formas de apropriação dos recursos aquáticos e implicam na perspectiva de trocas, repasses e heranças culturais, bens e conhecimentos intergeracionais" (Torres 2003: 105).

Ao abordar o tema do envelhecimento e a transferência intergeracional em uma comunidade pesqueira no estuário amazônico, a autora observou que a categoria de idade influencia na dinâmica da atividade de pesca dependendo de alguns fatores como região geográfica, localidade, o tipo de produção, as características demográficas e as estratégias de vida, adotadas a longo prazo.

"Os mais velhos detêm grande parte dos recursos necessários para a continuidade dessa atividade, seus conhecimentos, crenças e valores são essenciais para a modificação 
da produção pesqueira [...] [Além disso, quanto à aposentadoria] [...] a ruptura com o mundo do trabalho como sendo uma experiência traumática tal como acontece em ambientes urbanos, não foi percebida na sociedade pesqueira em estudo, sugerindo que nesse cotidiano, existem oportunidades de participação, com esse modo de vida. $\mathrm{O}$ trabalho extremamente integrado com a vida doméstica familiar e social propicia a valorização dos mais velhos" (Torres 2003:106).

Podemos afirmar, a partir das considerações do campo, que o mesmo foi observado no caso de Alter do Chão. A família de pescadores a qual estreitamos laços e que com freqüência nos levavam em suas pescarias era uma família muito numerosa e que mantinham uma rede integrada de atividades muito interessante, não só com a pesca (aqui re-atualizando ou ritualizando o que estamos chamando de polivalentes), mas também com outras atividades remuneradas, inclusive, no ramo da construção civil onde o mais "velho" da "turma", Seu "Mapará" de 70 anos, aposentado na profissão de pescador, era sempre escalado na divisão dos afazeres, sempre com a justificativa de que "inteirar o pirão" era preciso e o trabalho ficava menos laborioso, menos penoso para todos. Seu "Mapará" é o irmão mais velho de "Bodó" pertencente a uma família também muito grande, é o único que tem embarcação própria e com freqüência é quem comanda as pescarias apoiados por "Charutinho" e "Piaba", os sobrinhos que são exímios pescadores. Dessa forma, reconhecemos a assertiva de Torres (2003) quando observa que "Os mais velhos, ancorados nas suas experiências e conhecimentos, continuam orientando a família no uso dos recursos, desempenhando importantes papéis familiares e no cotidiano da pesca" (Torres 2003: 107). Contudo, não foram poucas as vezes que vimos "Seu Mapará" integrar a uma equipe de pessoas parentes para construir calçada, fossa ou cobrir de palha as casas e terrenos organizados para grandes eventos na vila.

\section{ALGUNS DADOS HISTÓRICOS E PERCEPÇÕES ATUAIS}

Retomando o conjunto das preocupações deste ensaio, no que tange as novas configurações da vila e suas implicações, vislumbramos familiarizar o leitor ou mesmo situar os efeitos globalizados ou globalizantes das forças políticas, econômicas e culturais que atuam no território aqui examinado. Uma das possibilidades de produzir insights ao entendimento, pelo menos em parte, do que ocorre atualmente é recorrer a dados históricos ou, na pior das hipóteses, a interpretação de dados históricos. Uma passagem de Dulcet (1999) em pequeno trecho de sua dissertação de mestrado pode nos oferecer um ponto de partida.

"Desde a década de 70 o turismo irrompe como motor da vida econômica em Alter. Desde então, os incrementos das atividades relacionadas com ele têm deslocado para as famílias locais o interesse em relação a outras formas de produção. É bem provável que em épocas anteriores a pesca e a coleta, assim como a caç, representassem a base das transaçôes ou, no mínimo, da dieta dos 
moradores. Mas, hoje em dia, sai mais em conta comprar um quilo de farinha de mandioca que elaborá-la domesticamente, considerando que o tempo empregado para o preparo pode ser investido em outra atividade com maior retorno" (Dulcet 1999: 26, grifo nosso).

A hipótese ensejada por Dulcet "É bem provável que em épocas anteriores a pesca e a coleta, assim como a caça, representassem a base das transações ou, no minimo, da dieta dos moradores" pode encontrar embasamento em indícios de tempos longínquos através de documentos e registros históricos de missionários e viajantes da primeira metade do século XVIII e XIX agregando, por vezes, informações sobre as técnicas utilizadas pelos primeiros habitantes da vila.

"Vila, distante quatro léguas de Santarém na margem esquerda do Tapajós, junto a um lago: nada tem de notável senão sua posição vantajosa junto a um morro [...] seus habitantes quase todos índios chegam a seiscentos e noventa e nove, com igreja paroquial em suficiente estado dedicada a Nossa Senhora da Saúde, e vigário. Cultivam os mesmos habitantes cacau, porém a pesca faz quase a comum ocupação dos índios" (Ignácio Accioli de Cerqueira e Silva - "Coreografia Paraense", às vésperas da Cabanagem apud Canto 2014: 17).

“Em 1852, em Alter do Chão no estado do Pará, índios semicolonizados lanceavam peixes à noite, usando feixes flamejantes feitos com frondes de palmeiras" (Bates 1864 apud Smith 1979).

O naturalista João Barbosa Rodrigues, quando de uma expedição científica ao rio Tapajós, nos deixou a seguinte descrição sobre Alter do Chão:

"Raiava o dia quando passávamos a ponta do cururu, lugar onde torna-se a estreitar o rio a que um elevado monte de forma cônica, para quem começa a subir o rio, dá um aspecto bonito a entrada da enseada onde está plantada a vila de Alter do Chão, que confusamente se avista de bordo, na margem oriental. Esta povoação está em completa decadência; reina a miséria e as vezes mesmo a fome. Consta de quarenta casas de palha. Tem uma escola publica freqüentada por 28 alunos. Os habitantes empregam-se na pesca ou na extração da borracha, para que abandonam seus lares. Lavoura não existe, a não ser rocinhas de mandioca ou de bananas, para o sustento próprio, assim como não há indústria alguma, quando, entretanto, possuem terras férteis e a proximidade da cidade e do centro comercial os convida ao trabalho" (João Barbosa Rodrigues apud Canto 2014: 18).

Outros indícios sustentam teses mais recentes a respeito da inexistência, de fato, de uma economia pesqueira (stricto sensu) na região amazônica. Que o homem amazônico "sempre" esteve ligado às práticas agrícolas, a caça e ao extrativismo como mantenedores de suas necessidades básicas e de suas relações de troca.

"Muito embora a pesca tenha sempre se constituído numa das mais importantes atividades econômicas do Amazônida, não podemos falar, do ponto de vista histórico, que inicialmente houve na região uma economia pesqueira propria- 
mente dita onde sobressaísse a figura do pescador, tal como hoje a concebemos. Desde as comunidades tipicamente indígenas não temos uma "profissionalização" do pescador. O mesmo índio que pesca, caça. A pesca não constituía a única atividade econômica, mas era complementar da caça [...] com a chegada do europeu, que vai ocupar o espaço amazônico inicialmente em busca das drogas do sertão (séc. XVII) e posteriormente pela expansão da economia extrativista (fins do séc. XVIII), sobretudo da borracha, que trouxe consigo o costume das práticas agrícolas, vai surgir a figura do "pescador-lavrador", ou seja, o homem desenvolverá contemporaneamente para seu sustento os recursos mais próximos à sua disposição; os rios (lagos e mar) e a terra, nunca porém sendo um "especialista" de atividade exclusiva" (Mello 1985: 33-34).

Mello (1985) também cita outro estudioso que corrobora com suas argumentações e nos informa sobre as estratégias que os moradores e os chefes de família da costa paraense [região do Salgado] adotavam em sua luta diária nas "entressafras".

"A pesca é mais amena e menos arriscada e o pescador não é propriamente um profissional: reúne elle o typo misto de agricultor-pescador sem ser, na expressão legal desses vocábulos, nem uma cousa nem outra, porque não está apparelhado para exercer essas profissões. Como lavradores, raros são os que possuem terras e seus instrumentos agrários são a enxada, a taceira ('Tacira", tupy), o machado e o terçado e roçam as terras devolutas do Estado ou nas terras do patrimônio da 'mãe velha' (Intendência). Como pescadores, povoam na 'safra' (inverno) do peixe os rios, canaes, mupeúas, restingas (corôas) e igarapés formados e banhados pelo mar e pelo fluxo das marés, mal agasalhados em pequenas curiácas, montarias e simples 'cascos' (sem falca e sem pavez com rodelas de prôa e pôpa de Tujuco, Talude) e de espinhel (tiradeira) tarrafa ou linha de mão, utensílios quase sempre emprestados a trôco de quinhão de peixe colhem o saboroso pescado nos grosso da piracêmas...passada a 'safra', mais de $60 \%$ dos pescadores paraoáras, do Salgado, deixam as águas e se destinam a outros mestres: uns vão desmanchar os roçados; outros vão abrir as roças de verão..."(Hurley 1933: 14-15).

Furtado (1987), por sua vez, observou na localidade de Marapanim (litoral do nordeste paraense) que o mesmo fenômeno ocorria até poucas décadas atrás, inclusive, apresentando certo grau de especialização da atividade pesqueira, mas tendo por base de sua economia a presente agricultura. Assim, entendemos que a pesca chegou a desempenhar ao longo da história da região, até pouco tempo atrás, um papel de atividade econômica complementar - nem por isso menos fundamental - quer $\mathrm{da}$ caça, do extrativismo vegetal e/ou da Agricultura. "A "profissionalização" da pesca artesanal é fenômeno já da segunda metade do século e resultará maior penetração de interesses capitalistas no setor, fato que historicamen- 
te tem suas origens no surgimento de uma comercialização intensa do peixe" (Mello 1985:38). Dentre outros fatores, que contribuíram para um crescimento comercial da pesca na região podemos citar a introdução do motor nas embarcações, a expansão do sistema rodoviário e a urbanização acelerada.

"A construção de estradas que ligavam os centros produtores aos centros consumidores veio romper o relativo isolamento em que viviam agrupamentos humanos dessa região facilitando enormemente as transações comerciais. $\mathrm{O}$ resultado imediato foi a entrada de produtos industrializados característicos do estilo de vida urbano que passaram a ser almejados pelos interioranos e exigindo uma produção maior de seus habitantes" (Loureiro 1983 apud Furtado 1987).

O curioso é notar que os enquadramentos históricos dessa demanda e o aumento da produtividade na atividade pesqueira são perfeitamente visíveis no município de Santarém, mas o mesmo não aconteceu no distrito de Alter do Chão apesar de possuir os recursos ambientais necessários, sem contar com um complexo sistema lacustre, propício para criadouros e viveiros, com uma ictiofauna abundante e com possibilidades de planos de manejo sustentáveis (Costa 2005). A questão é tão evidente, que cerca de $90 \% 0^{20}$ do pescado comercializado, hoje na vila, são transportados da cidade de Santarém, e os barraqueiros e donos de restaurantes e pousadas adquirem as espécies de peixes mais valorizados e procurados para o consumo dos turistas, como o Tambaqui (Colossoma ma- cropomum), Pirarucu (Arapaima gigas) e o Tucunaré (Cichla spp), diretamente dos mercados de peixe da cidade, inclusive, a maioria com fornecedores fixos.

As poucas "vendas de peixe" na vila [basicamente cinco] também recebem variadas espécies de peixes trazidas por caminhões da cidade ou mesmo buscadas pelos próprios donos através do ônibus de linha (Santarém-Alter) em caixas de isopores de tamanhos variados, dependendo da encomenda. Diante do exposto e o gradiente de percepções, o que deveríamos concluir com tais informações? Que não há pescarias ou pescadores em Alter do Chão? Ou que estes não teriam interesse em vender sua produção para o mercado local? Que o quê predomina é a pesca de subsistência e tão somente? As razões profundas deste estado de coisas em relação ao comércio de peixes na vila ainda estão em fase de investigação, por ora ficaremos com um comentário de um associado da colônia de pescadores do Núcleo de Base de "Alter" em conversa informal na frente de seu comércio.

"Em reunião da Z-20"21 eu já propus pra gente fazer assim que nem o pessoal faz. por aí... um criadouro de peixe, pra gente sempre ter né...mas o povo aqui num quer...olhe, tem muito lago bom aqui! Tem o lago da Piranha, tem o lago do Jacaré... tem um outro aqui chamado Ponta do Trilheiro, não sei se tu conbece? Mas o povo é muito desunido... todo mundo só quer saber do seu...uns diz que não tem condição outros diz que num quer mesmo...ai fica difícil ..." (Seu Piraíba, na taberna de sua casa, junho de 2016). 


\section{ALGUMAS CONSIDERAÇÕES FI- NAIS OU PARA TERMINAR "EM- BARCADO"}

É por uma razão muito consciente que a prática e a imersão etnográfica com o objetivo de apreender e aprender com outra cultura se faz presente neste breve estudo. Concebemos a prática como processo de aprendizado empírico e é, sobretudo, lançar-se aos fatos para, assim, almejar conhecê-los. A experiência, por seu turno, é o acúmulo da prática somada à destreza assimilada dos erros e acertos, o saber experimentado várias vezes, é a sedimentação do conhecimento e memória comunicáveis na acepção benjaminiana, resultado do "modo de vida que pressupõe o mesmo universo de linguagem e de práticas, associando a vida particular à vida coletiva e estabelecendo um fluxo de correspondências alimentado pela memória" (Meinerz 2008: 18). Se assim consideramos também o processo de conhecimento em Antropologia, por intermédio da etnografia, como alude Magnani (2009) sobre sua especificidade, podemos tecer algumas breves considerações de parte do que experimentamos, refletimos e conjecturamos a respeito do objeto abordado.

Alter do Chão hoje vive exposta a dinâmica do turismo local e global, com ele aos ciclos de festividades incluindo as festas de santos católicos e da padroeira, ao festival do Sairé e dos Botos que lhe dão visibilidade regional, nacional e internacional trazendo consigo um emaranhado de símbolos, significados e disputas em diversas esferas da vida social. E mais, recentemente, a um intenso fluxo de cientistas, transeuntes (viajeros, turistas, forasteiros, artistas de rua) e pesquisadores das mais diversas áreas e países que aportam nesta localidade com amplos interesses. Com tudo isso o aumento da especulação imobiliária é fator mais que presente agrupado aos demais aspectos de tensões territoriais e comerciais reelabora os modos tradicionais de relacionamento da população nativa com o ambiente natural, com a cidade, com as diversas pessoas que por ali transitam. Moradores antigos vendem suas propriedades a novos moradores e vão constituindo periferias em bairros e comunidades relativamente distantes das áreas centrais da vila.

Assim, os pescadores artesanais que analisamos estão inseridos neste contexto. Constroem novas percepções de mundo e incorporam novos valores demonstrando certo nível de ambiguidade, possuem, contudo, baixa articulação política para reivindicar melhorias no estabelecimento de suas práticas e alienados dos recursos materiais necessários ao seu trabalho por causa do baixo poder aquisitivo tendem a utilizar de todas as estratégias possíveis para sobreviver, inclusive deslocamentos para cidades vizinhas ou mesmo distantes em outros estados com serviços já empreitados.

Nesta situação, as distintas práticas de captar recursos, mediante a venda da força de trabalho, fundamentam o ser polivalente como responsável de sua dinâmica do dia a dia. Constitui, portanto, uma "artimanha do viver" da mesma forma de quando o rio não está para peixe. O que vale é não ficar $p a-$ nema! ${ }^{22}$, segundo a visão dos mesmos. 
Dessa forma, buscar etnografar uma família de pescadores artesanais em Alter do Chão significou num primeiro momento se aventurar a pescar no duplo sentido, o sentido estrito da palavra - fisgar o peixe - e o sentido metafórico - "fisgar o sentido das ações" - dos arranjos, dos fragmentos, das estratégias de sobrevivência para, enfim, tentar "inteirar o pirão".

\section{NOTAS}

* Agradeço à pesquisadora Débora Fernandes Pereira Machado e ao Professor Rubens Elias da Silva pelas leituras atentas a versões anteriores deste artigo. E também a Bibine Giniotte, Susana Simón Tenorio e Damian A. Borovka pelas gentis traduções e pela alegria de conhecê-los durante suas viagens.

${ }^{1}$ Adotamos a nomenclatura "Vila", pois, entendemos que é assim que os moradores de Alter do Chão a reconhecem e se referem no cotidiano. Dificilmente se ouve falar em distrito, apesar de esta ser sua categoria político-administrativa oficial.

${ }^{2}$ Por exemplo, a perspectiva marxista através de autores como Maurice Godelier e Gyorgy Lukács. Outra referência importante é o estudo de Mello, Alex Fiúza. 1985. A pesca sob o capital: a tecnologia a servicgo da dominação. Belém: UFPA.

${ }^{3}$ Expressões nativas encontradas em trabalho de campo remetendo a ideia de "incrementar a renda" ou "acrescentar o fator alimento". Pode-se aludir também a expressão em inglês 'to muddle through' que significa 'se virar'.

${ }^{4}$ Explanação de apresentação em Palestra: "As populações tradicionais e os grandes projetos da Amazônia: a Usina Hidrelétrica de Tucuruí, 30 anos depois" Palestrante:
Prof. Dra. Cecília Basile. Universidade Federal do Pará, Belém - PA. In: Seminários "Interdiálogos" com Cecília Basile (Laboratório Antropologia dos Meios Aquáticos) Projeto RENAS/LAMAq/PEC/MPEG, janeiro de 2016. Disponível em: $<$ https://www. youtube.com $/$ watch? $\mathrm{v}=\mathrm{PO} 0 \mathrm{cG}$ izirE $>$. Acesso em 06/01/2017.

${ }^{5}$ Importante discussão sobre a identificação de diversas categorias de pescadores (lavradores, artesanais, assalariados) pode ser visto em Diegues, Antonio Carlos. 1983. Pescadores, camponeses e trabalhadores do mar. São Paulo: Ática.

6 "Processos ecossociais são entendidos como um irrevogável metabolismo do pescador com a natureza, cujo trabalho torna-se condição sine qua non da produção e reprodução social da pesca artesanal enquanto categoria constitutiva e constituída das formas de ser e das determinações de existência socioeconômica, culturais e ecológicas" (Ramalho 2016: 1)

${ }^{7}$ Conferir matéria especial publicada no jornal Gazeta Santarém, 16 de fevereiro de 2013, sob o título "a demarcação da Terra indígena Borari pode agravar conflitos, se for incluído pólo Turístico já consolidado". Disponível em www.gazetadesantarem.com.br

${ }^{8}$ É o caso da representatividade política e dos recursos da prefeitura de Santarém destinados aos eventos mais importantes na vila, como por exemplo, a "Festa do Sairé" e o "Festival dos Botos".

${ }^{9}$ Foram inventariadas 647 residências, das quais apenas $36 \%$ (por se tratar de vila balneária) pertenciam a moradores permanentes.

${ }^{10}$ Observações de campo realizadas no período de um ano entre o inicio de 2016 e o inicio de 2017 não converge com tal afirmativa. O mesmo menciona Carvalho (2016) a respeito do decaimento das ativi- 
dades de roça, caça e pesca em "Alter" em contraponto da dependência da economia local em relação ao turismo.

${ }^{11} \mathrm{O}$ autor procura explorar uma configuração modelar a respeito do componente ético que acredita constituir uma ordem moral do camponês em diferentes lugares e tempos, sem, contudo, deixar de considerar a processualidade histórica dos sujeitos.

${ }^{12}$ Vale ressaltar que este autor propõe uma nova definição de "condição camponesa" que o situe no contexto dos dias atuais e preencha as lacunas deixadas pela tradição dos estudos camponeses. Tal definição pode ser consultada em Ploeg (2008: 40).

${ }^{13}$ Estamos seguindo as pistas de Ramalho (2016) para quem estas categorias são produtivamente analisadas enquanto categorias êmicas. Segundo o autor elas apontam para modos de interpretação dos pescadores do próprio fazer-se pescador.

${ }^{14}$ Refiro-me ao "tempo de antigamente" em que a vila configurava apenas um balneário pacato, que por vezes ficasse movimentada durante a vazante do rio, onde as praias emergiam e atraiam gente de toda parte.

${ }^{15}$ Optamos por utilizar nomes fictícios, de preferência nomes de peixes conhecidos da região, como forma de preservar a identidade dos pescadores referidos na pesquisa.

${ }^{16} \mathrm{Meu}$ apelido entre os pescadores.

${ }^{17}$ O Programa Bolsa Família compreende a concessão de benefícios de pagamentos mensais às famílias consideradas pobres ou extremamente pobres, com requisitos para manutenção estabelecidos em lei federal, com valor definido, de caráter temporário, não gerando direito adquirido. Foi instituído pela Lei $n^{\circ} 10.836 / 2004$, regulamentada pelo Decreto no 5.209/2004.

${ }^{18}$ Espécies de golfinhos de água doce muito comum na região amazônica. Duas es- pécies são predominantes nesta região, o boto tucuxi (Sotalia fluviatilis) e o boto vermelho ou cor-de-rosa (Inia geoffrensis).

${ }^{19}$ Encaramos a cultura, neste texto, a partir da perspectiva do antropólogo norueguês Fredrik Barth (2005), ou seja, como um conjunto de idéias e conceitos compartilhados, mas "ideias que transbordam seus limites e se difundem de forma diferenciada, criando uma variedade de agregados e gradientes" (Barth 2005: 17)

${ }^{20} \mathrm{~A}$ informação se baseia em conversas informais com donos de vendas de peixe no perímetro da vila. Os mesmos informam que em condições favoráveis ocorre de buscar o pescado em comunidades adjacentes como Maripá ou Jari.

${ }^{21}$ Colônia de pescadores fundada por volta de 1920 e abrange o município de Santarém e comunidades adjacentes.

${ }^{22}$ Panema: Diz-se, em geral, do indivíduo que tem pouca sorte na caça, na pesca e nos amores. "- é quando o caboco tá desgraçado, não pega nada nem gripe...” (informação verbal).

\section{REFERÊNCIAS}

Barth, F. 2005. Etnicidade e o Conceito de Cultura. Antropolítica 19:15-30, 2. Sem. Niterói

2000a. O guru e o iniciador: transações de conhecimento e moldagem da cultura no sudeste da Ásia e na Melanésia, in: O guru, o iniciador e outras variações antropológicas. Rio de Janeiro: Contra Capa Livraria.

2000b. A Análise da Cultura nas Sociedades Complexas, in $O$ guru, o iniciador e outras variações antropológicas. Rio de Janeiro: Contra Capa Livraria.

Begossi, A. et al. 2004. Ecologia de pescadores da Mata Atlântica e da Amazônia. São Pau- 
lo: Hucitec, Nepam/Unicamp - Nupaub/ Usp: FAPESP.

Benjamim, W. 1994. Experiência e pobreza, in Magia e Técnica, Arte e Política. Ensaios sobre literatura e história da cultura. Obras Escolhidas, v.1, $4^{\circ}$ edição, São Paulo: editora Brasiliense.

Canto, S. A. 2014. Alter do Chão e Sairé: contribuição para a história. Santarém; Editora e Artesanato Gráfico Tiagão.

Carvalho, L. G. 2016. Tradições devotas e lúdicas inovações: o sairé em múltiplas versões. Sociologia \& Antropologia 6(1):237-259.

Carvalho, V.; Tura, L. 2006. A expansão do monocultivo de soja em Santarém e Belterra: injustiça ambiental e ameaça à segurança alimentar. Belém: FASE.

Castro, E. 1997. Território, biodiversidade e saberes de populações tradicionais, in: Faces do trópico úmido: conceitos e questões sobre desenvolvimento e meio ambiente. E. Castro \& F. Pinton.Belém: Cejup: UFPA-NAEA.

Cortês, J. C.; D’antona, A. O. 2016. Fronteira agrícola na Amazônia contemporânea: repensando o paradigma a partir da mobilidade da população de Santarém-PA. Boletim do Museu Paraense Emílio Goeldi. Ciências Humanas 11(2):415-430.

Costa, L. R. F. da. 2005. Ecologia de lagos da planície inundada do Baixo Tapajós: diversidade, estrutura de comunidade de peixes e percepções socioeconômicas dos moradores de Alter do chão, Santarém-PA. Tese de Doutorado - Programa de Pós-Graduação em Zoologia: Universidade Federal do Pará/ Museu Paraense Emílio Goeldi, Brasil.

Cruz, M. J. M. 2007. Territorialização camponesa na várzea da Amazônia. Tese de Doutorado. Programa de Pós-Graduação em Geografia Humana - FFLCH, Universidade de São Paulo, Brasil.
DaMatta, R. 1978. O oficio de Etnólogo, ou como ter "Anthropological Blues", in $A$ aventura Sociológica, pp. 23-35.Organizado por E. O. Nunes. Rio de Janeiro: Zahar.

Dawsey, J. C. 2013. De que riem os bóias-frias?: diários de antropologia e teatro. São Paulo: Terceiro Nome.

Diegues, A. C. 1995. Povos e mares: leitura em socioantropologia marinha. São Paulo: NUPAUB-USP.

1983. Pescadores, camponeses e trabalhadores do mar. São Paulo: Ática.

Dulcet, S. R. 1999. A produção simbólica da festa do Çairé: drama, cultura e representação em Alter-do-Chão, Santarém, Pará. Dissertação de Mestrado. UFPA, Belém, Brasil.

Furtado, L. 1981. Pesca artesanal: Um delineamento de sua história no Pará. Boletim do Museu Paraense Emílio Goeldi, série Antropologia, 79, $50 \mathrm{pp}$.

1987. Curralistas e redeiros de Marudá: Pescadores do litoral do Pará. Belém, CNPq/MPEG. 366p.

1990. Características Gerais e Problemas da Pesca Amazônica no Pará. Boletim do Museu Paraense Emílio Goeldi 6(1): 41-93.

1997. Problemas ambientais e pesca tradicional na qualidade de vida na Amazônia, in Amazônia desenvolvimento, sociodiversidade e qualidade de vida. Organizado por L. Furtado. Belém: UFPA-NUMA.

1993. Pescadores do rio Amazonas: um estudo antropológico da pesca ribeirinha numa área amazônica. Belém: Museu Paraense Emílio Goeldi. 486p. (Coleção Eduardo Galvão).

Furtado, L.; Nascimento, I. H. 2002. Traços de uma comunidade pesqueira do litoral amazônico: relato sobre organização em comunidade haliêutica, in Gente e ambiente no mundo da pesca artesanal, pp.173-190. 
Organizado por L. Furtado e H. D. A. B. Quaresma. Belém: MPEG (coleção Eduardo Galvão).

Galeski, B. 1977. Sociologia del campesinato. Barcelona: Ediciones Península.

Hébette, J.; Magalhães, S. B.; Maneschy, M. C. 2002. Contemporaneidade do campesinato na Amazônia oriental, in No mar, nos rios e na fronteira: faces do campesinato no Pará. Organizado por J. Hébette, S. B. Magalhães e M. C. Maneschy. Belém: UFPA.

Houaiss, A; Villar, M. S. 2004. Minidicionário Houaiss da lingua portuguesa. Rio de janeiro: Objetiva.

Hurley, J. 1933. No domínio das águas. História da Pesca no Pará. Belém. Typografia Dom Macedo Costa.

Lima, M. G. M. 2002. Migração - uma estratégia de sobrevivência para o pescador artesanal?, in Gente e ambiente no mundo da pesca artesanal. Organizado por L. Furtado e H. D. A. B. Quaresma .Belém: MPEG, 2002. P.173-190 (coleção Eduardo Galvão) 2008. Mobilidade geográfica como estratégia de sobrevivência de pescadores artesanais na Amazônia: o caso de Cubatão em Icoaraci, Pará. Dissertação de Mestrado - Programa de Pós-Graduação em Geografia do Instituto de Filosofia e Ciências Humanas da Universidade Federal do Pará. Belém/PA.

Loureiro, V. R. 2009. A Amazônia no século XXI - novas formas de desenvolvimento. São Paulo: Editora Empório do Livro.

1983. Os parceiros do Mar: Natureza e conflito social na pesca da Amazônia. Dissertação de Mestrado em Sociologia. Instituto de Filosofia e Ciências Humanas - Universidade Estadual de Campinas. São Paulo, Brasil.

Magnani, J. G. C. 2009. Etnografia como prática e experiência. Horizontes Antropológi$\cos 15(32): 129-156$.
Marques, J. G. W. 1991. Aspectos Ecológicos na Etnoictiologia dos pescadores do Complexo Estuarino-Lagunar Mundaú-Manguaba, Alagoas. Tese de Doutorado - Programa de Pós-Graduação em Ecologia da Universidade Estadual de Campinas. Unicamp: Campinas, Brasil.

Martins, E. V. 2009. Dinâmica da economia e das relações do trabalho da pesca artesanal no município de Santarém-PA. Dissertação de Mestrado - Programa de Pós-Graduação em Desenvolvimento Sustentável do Trópico Úmido. UFPA: Belém, Brasil.

Meinerz, A. 2008. Concepção de Experiência em Walter Benjamin. Dissertação de Mestrado. Programa de Pós-Graduação em Filosofia. UFRGS, Porto Alegre.

Mello, A. F. 1985. A pesca sob o capital: a tecnologia a serviço da dominação. Belém: UFPA. 1995. Movimentos sociais na pesca: breve balanço bibliográfico: novos desafios teóricos. Boletim do Musen Paraense Emilio Goeldi 11(1):19-39 (série antropologia) 1994. Capitalismo, pesca e empobrecimento na Amazônia: a contra face da modernização, in A Amazônia e a crise da Modernização. Organizado por M. A. D’Incão e I. M. Silveira.Belém: MPEG.

Mello, A. F.; Furtado, L.; Leitão, W. 1993. Povos das Águas. 1. ed. Belém: Coleção Eduardo Galvão/MCT/CNPq/MPEG.

Moreira, E. S; Hébette, J. 2009. Metamorfoses de um campesinato nos Baixo Amazonas e Baixo Xingu paraenses, in Diversidade do campesinato: expressões e categorias, Volume I, pp.187-207. Organizado por E. P. Godoi, M. A. Menezes e R. A. Marin. São Paulo, Editora da UNESP; Brasília, NEAD.

Moreno, L. T. 2015. A luta para pescar: reconhecimento e direito social dos pescadores artesanais. Revista Pegada 16(2): 16-42. 
Oliveira, M. F.; Ribeiro Neto, F. B. 1989. Estratégias de sobrevivência de comunidades litorâneas em regiões ecologicamente degradadas: o caso da Baixada Santista. Programa de Pesquisa e Conservação de áreas úmidas no Brasil. São Paulo: Ford; UICN; IOUSP, 132p.

Ploeg, J. D. 2008. O que é, então, o campesinato?, in Camponeses e impérios alimentares: lutas por autonomia e sustentabilidade na era da globalização, pp.33-74. Porto Alegre, Editora da UFRGS.

Ramalho, C. W. N. 2016. Pescados, pescarias e pescadores: notas etnográficas sobre processos ecossociais. Boletim do Musen Paraense Emílio Goeldi. Ciências Humanas 11:391-414.

Rodrigues, J. B. 1875.Rio Tapajós. Rio de Janeiro: Tipografia Nacional.

Santana, G. 2002. Pesca industrial um problema socioambiental, in Gente e ambiente no mundo da pesca artesanal, pp.173-190. Organizado por L. Furtado e H. D. A. B. Quaresma. Belém: MPEG (coleção Eduardo Galvão).

Shanin, T. 1980. A definição de camponês: conceituações e desconceituações. Estudos CEBRAP 26. Editora Vozes.

.1976. Naturaleza y lógica de La economia campesina. Barcelona: Anagrama. Silva, R. E. 2012. Guiados por Mares \& Peixes: memória social, inovação tecnológica e o processo de fragmentação na pesca comercial simples em duas comunidades pesqueiras no Rio Grande do Norte. Tese de Doutorado - Programa de Pós-Graduação em Sociologia. UFPB: João Pessoa, Brasil.

2014. Socioantropologia da Pesca: estudos etnográficos sobre populacõos costeiras no Nordeste Brasileiro. João Pessoa: Ideia.

Silva, J. G.; Del Grossi, M. E. 1998. O novo rural brasileiro: ocupações rurais não-agrícolas. Campinas: IE/UNICAMP.
Smith, N. J. H. 1979. A pesca no rio Amazonas. Manaus: CNPq; INPA.

Torres, V. L. S. 2003. Redes do envelhecimento numa sociedade pesqueira do estuário amazônico. Simpósio Amazônia, Cidades e Geopolitica das Águas, Belém. Amazônia, Cidades e Geopolítica das Águas (Resumo) Woortman, K. 1990. "Com parente não se neguceia”: o campesinato como ordem moral. Anuário Antropológico 87: 11-73. Rio de Janeiro, Tempo Brasileiro; Brasília, Editora da UnB.

Recebido em 10/06/2017

Aprovado em 02/08/2017 